\title{
A HUGE SILENT INTRACRANIAL HYDATID CYST IN AN ADULT MALE: A CASE REPORT
}

Sonal Amit ${ }^{1}$, Priyanka Chand ${ }^{2}$, Asha Agarwal ${ }^{3}$, Suman Lata Verma ${ }^{4}$, Anil Kumar ${ }^{5}$

\section{HOW TO CITE THIS ARTICLE:}

Sonal Amit, Priyanka Chand, Asha Agarwal, Suman Lata Verma, Anil Kumar. "A Huge Silent Intracranial Hydatid CYST in an adult Male: A Case Report". Journal of Evolution of Medical and Dental Sciences 2015; Vol. 4, Issue 29, April 09; Page: 5073-5077, DOI: 10.14260/jemds/2015/740

ABSTRACT: Hydatid disease of the brain is a rare parasitic infestation caused by larval stage of Echinococcus granulosus. It has an insidious onset with a slow rate of growth resulting in late diagnosis. Its occurence is rare in India, being endemic in Mediterranean countries and Middle East. We report a case of a huge, slow-growing, silent intracranial left parieto-temporo-occipital hydatid cyst in an 18 year old male presenting as a large cystic space occupying lesion.

KEYWORDS: Echinococcus, intracranial, hydatid cyst.

INTRODUCTION: Hydatid disease is caused by the tape worms of the genus Echinococcus. The infection occurs most commonly by Echinococcus granulosus presenting as unilocular cyst and less commonly by Echinococcus multilocularis presenting as multilocular cyst. It commonly seen in the temperate climate of cattle raising regions of the world where it is considered an important public health problem.[1] This public health problem is influenced by the socioeconomic status of the population who earn their livelihood by rearing cattle.[2] Members of the canine family act as definitive hosts while, the intermediate hosts include sheep, cattle, pigs and horses. Humans are accidental intermediate host who get infected by ingesting the contaminated food and water.[2] Cerebral hydatid cyst comprises of $1-2 \%$ of all cases of hydatid disease presents commonly as a unilocular cystic space occupying lesion. This case is reported for its rarity as well as its unique features of presentation in a non-endemic area.

CASE REPORT: An 18-year old male hailing from a low socioeconomic group came presented with severe headache and projectile vomiting of a week's duration. There was complaint of mild headache for nearly three years prior to this sudden presentation. However, his ability to perform daily activities precluded him from seeking medical attention. He off and on took ayurvedic medicines but, to no relief. There was no history of prolonged fever, trauma, blurring of vision and abdominal pain or any difficulty in urination and defecation. On neurological examination, the boy was oriented to person, time and place. Bilateral papillary reflexes, sensory systems and cranial nerve examination were normal. However, motor examination revealed right hemiparesis with a power grade of 3/5 in all muscles with hypertonia and exaggerated deep tendon reflexes and planter extensor. Magnetic resonance images of brain revealed a large lobulated well defined complex cystic space occupying lesion having multiple internal well defined cystic areas or daughter cysts exerting pressure effect to the surrounding brain structures resulting in mild increase in intracranial pressure (Figure 1A). The radiological findings suggested the diagnosis of intracerebral hydatid cyst. CT scan of thorax and USG of abdomen revealed no cystic lesion. Hydatid serology for serum IgM yielded a positive reaction. Patient underwent open craniotomy and the cyst was resected in toto. 
The specimen was sent for histo-pathological examination. Grossly, a ruptured pearly white cyst wall was obtained measuring $8.0 \times 5.0 \mathrm{~cm}$ along with multiple small daughter cysts each measuring $1.0 \times 1.0 \mathrm{~cm}$ which were filled with clear fluid (Figure 1B). Sections were stained with haematoxylin and eosin method which revealed eosinophilic laminated cyst wall with the germinal layer having the scolices some attached to it and some lying free in the lumen (Figure 2A, B). The histopathological diagnosis of intracranial hydatid cyst was made.

Patient was administered broad-spectrum antibiotics, anticonvulsants, steroids, and albendazole. The post-operative recovery was smooth and at the time of discharge, the patient had improved symptomatically. Patient was followed for one year with no episode of recurrence.

DISCUSSION: In India the incidence of intracranial hydatid cysts is $0.2 \%$ of all intracranial space occupying lesions. ${ }^{[3-5]}$ Hydatid disease is endemic in cattle-and sheep-rearing regions of the world such as Central Europe, the Mediterranean countries, the Middle East, South America, Australia, New Zealand, and South Africa.[1] In India it is commonly seen in the Kurnool district of Andhra Pradesh, Madurai district of Tamil Nadu and in Punjab.[6,7] But this case hails from a non-endemic area in India i. e., Uttar Pradesh. Mostly the people from rural areas, living in close contacts with dogs and cattle are affected by accidental ingestion of the eggs contaminating the food articles and drinking water. The present case also comes from the rural area earning his livelihood from cattle rearing. The patient was from low socioeconomic strata with low sense of hygiene and cleanliness that might have led to this infection.

In literature, cerebral involvement is very rare ranging from 1-3\% after liver and lungs and children are more commonly affected than adults and are usually found in males.[8] Usually the hydatid cysts in brain are solitary, in contrast to other organs where they are usually multiple.[9-11] They are most often located supratentorially, with parietal lobe being the most common site affected due to major blood supply from middle cerebral artery.[12] The parietal lobe involvement was seen in all cases by Dharker et al[13] and three out of five cases by Balasubramanium et al.[14] The present case shows parieto-temporo-occipital involvement.

Rauf et al had reported that the growth of hydatid cyst in different organs of the body is variable. According to them the patient and parasite factors, location of organ of cyst, host reaction and presence of any complications effects the growth of the cyst. Compressible organs such as the lung or brain which provide free space facilitate their growth. The growth rate of the hydatid cyst of the brain is usually slow resulting in late presentation; various studies have reported the rate of growth ranging from $1.5-10 \mathrm{~cm}$ per year.[3-5]

The primary cysts are formed as a result of direct infestation of the larvae in the brain without demonstrable involvement of other organs. Intracranial hydatid cysts are commonly solitary. Multiple cysts occurs due to embolisation from hydatid cyst located in the heart.[12] Onal et al[1] and Lunardi et al[15] reported occurrence of multiple cysts in their studies. The primary cysts are fertile as they contain scolices and brood capsules hence, rupture of primary cyst can result in recurrence. The secondary multiple cysts results from spontaneous, traumatic or surgical rupture of the primary intracranial hydatid cyst and they lack brood capsule and scolices. The secondary intracranial hydatid cysts are therefore infertile and the resultant risk of recurrence after their rupture is negligible.[16] The histology sections of this case shows the brood capsules and the scolices which suggests that it is a primary hydatid cyst of brain. 
Clinically and radiologically, intracranial hydatid could be confused with include arachnoid cyst, metastasis, tuberculosis, fungal infections, cerebral abscess and cystic tumors of the brain.[17] As the prognosis of intracranial hydatid cyst is very good if resected into to prevent recurrence and anaphylactic reaction, the suspicion of hydatid cyst should always be kept in mind while dealing with a young adult presenting with intracranial space occupying lesion.

\section{REFERENCES:}

1. Onal C, Erguvan-Onal R, Yakinci C, Karayol A, Atambay M, Dalal N. Can the reqirement of a diversion procedure be predicted after an uncomplicated intracranial hydatid cyst surgery?Pediatr Neurosurg 2006; 42(6): 383-6.

2. Wani RA, Wani I, Malik AA, Parray FQ, Wani AA, Dar AM. Hydatid disease at unusual sites. International Journal of Case Reports and Images 2012; 3(6): 1-6.

3. Dharker SR: Hydatid disease. In: Ramamurthi B, Tandon PN (eds) Text Book of Neurosurgery, 2nd edition. New Delhi: Churchill Livingstone; 1996. p. 535-44.

4. Raja Reddy D, Dayanand Rao B, Prabhakar V et al: Hydatid disease of the central nervous system. Indian J Surgery1972; 34:192.

5. Sardana VR, Dharker SR, Mittal RS et al: Multiple intracranial hydatid cysts. Neurol India 1991; 39: 205.

6. Bukte Y, Kamanoglu S, Nazaroglu H, Ozkan U, Ceviz A, Simsek M. Cerebral hydatid disease: CT and MR imaging findings. Swiss Med Wkly 2004; 134: 459-67.

7. Gupta S, Desai K, Goel A. Intracranial hydatid cyst: A report of five cases and review of literature. Neurol India 1999; 47: 214-7.

8. Altas M, Aras M, Serarslan Y, Davran R, Evirgen O, Yilmaz N. A medically treated multiple cerebral hydatid cyst disease. J Neurosurg Sci 2010 Jun; 54 (2): 79-82.

9. Cangiotti L, Muiesan P, Begni A, de Cesare V, Pouche A, Giulini SM, Tibero G: Unusual localizations of hydatid disease: A 18 year experience. G Chir1994, 15: 83-86.

10. Hussain a, Maqbool A, Hussain S, Athar M, Shakoo A, Amin MK: Studies on prevalence and organ specificity of hydatidosis in ruminents slaughtered at Karachi and Faisalabad abattoir.

11. Eckert J, Deplaes P: Biological, Epidemiological and clinical aspects of echinococcosis a zoonosis of increasing concern. Clinical microbial Rev 2004, 17: 107-135.

12. Ali M, Mahmood K, Khan P. Hydatid cysts of the brain: J Ayub Med Coll Abbottabad 2009; 21 (3).

13. Dharker SR Dharker RS, Vaishya ND, Sharma ML, Chaurasia BD. Cerebral hydatid cysts in central India. Surg Neurol 1977; 8: 31-34.

14. Balasubramanium V, Ramanujam PB, Ramamurthi B. Hydatid disease of the nervous system. Neurol India 1970; 18: 92-5.

15. Lunardi P, Missori P, Di Lorenzo N, Fortuna A. Cerebral hydatidosis in childhood: a retrospective survey with emphasis on long-term follow-up. Neurosurgery 1991; 29: 515-7.

16. Trivedi A, Shukla S, Singh. K, Sharma V. Giant intracranial hydatid cyst. J Pediatr NeuroSci 2007; 2: 72-4.

17. Bukte Y, Kamanoglu S, Nazanoglu H, Ozkan U, Ceviz A, Simsek M. Cerebral hydatid disease: CT and MR imaging findings. Swiss Med wkly2004; 134: 459-67. 


\section{CASE REPORT}

Figure 1: (A) MRI image showing well defined complex cystic lesion with multiple daughter cyst causing midline shift. (B) Gross specimen showing pearly white cyst wall with multiple smaller daughter cysts.

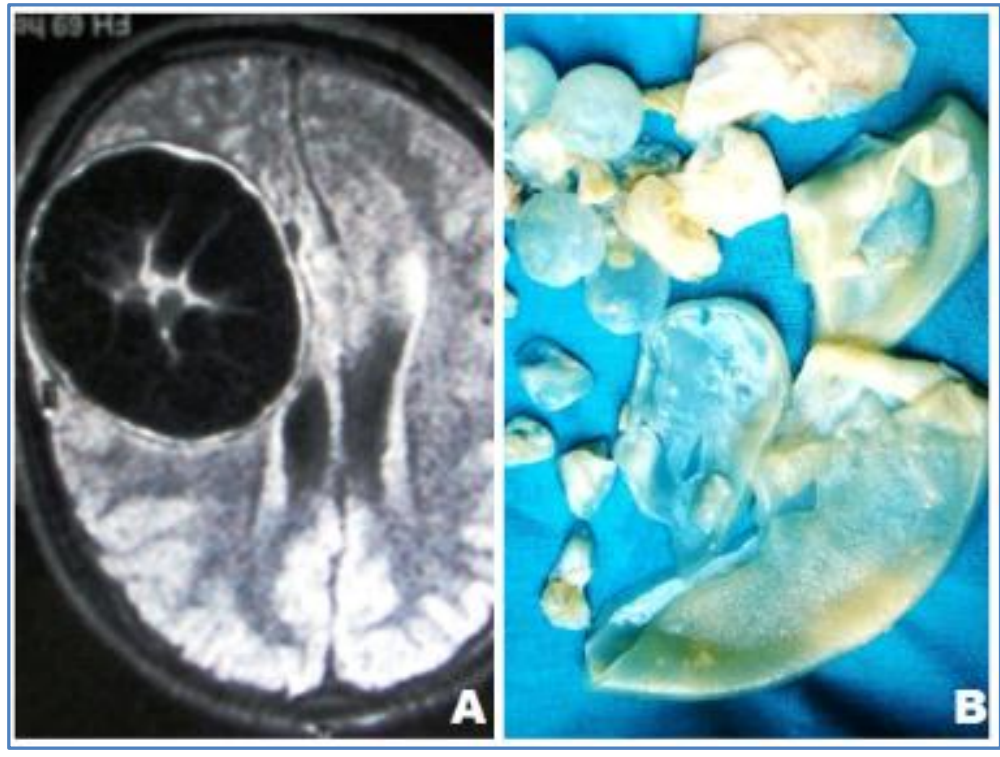

Fig. 1

Figure 2: (A) Low power view showing eosinophilic laminated cyst wall with multiple scolices (H\&E, $\mathrm{x} 100)$. (B) High power view of the same structures detailing the characteristic morphology (H\&E, $\mathrm{x} 400)$.

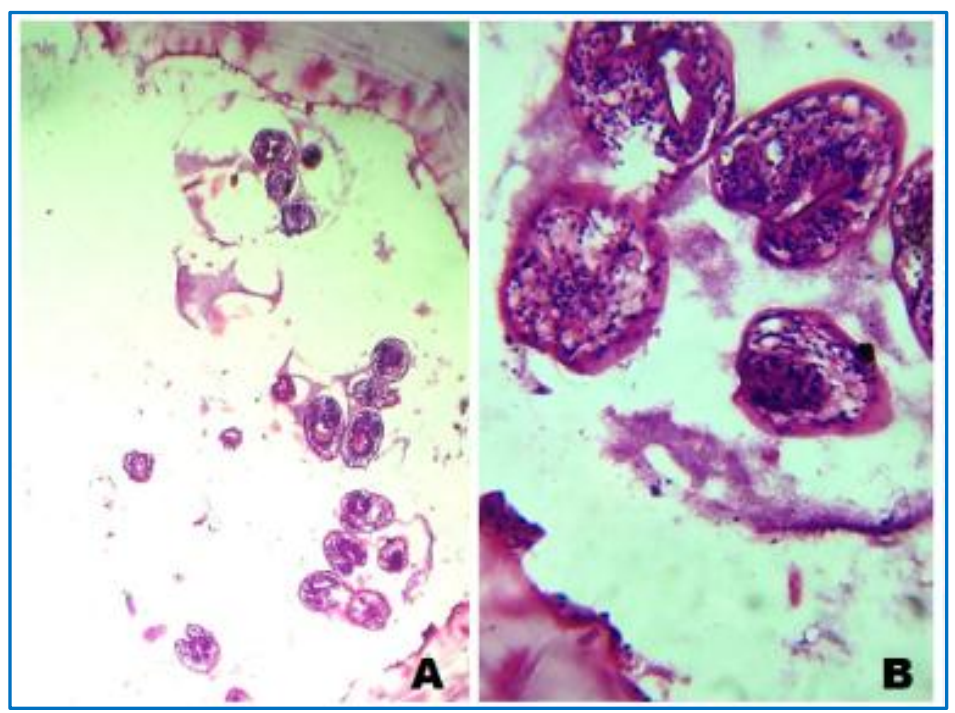

Fig. 2 


\section{AUTHORS:}

1. Sonal Amit

2. Priyanka Chand

3. Asha Agarwal

4. Suman Lata Verma

5. Anil Kumar

\section{PARTICULARS OF CONTRIBUTORS:}

1. Lecturer, Department of Pathology, GSVM Medical College, Kanpur.

2. Ex-Junior Resident, Department of Pathology, GSVM Medical College, Kanpur.

3. Professor, Department of Pathology, GSVM Medical College, Kanpur.

FINANCIAL OR OTHER COMPETING INTERESTS: None
4. Professor, Department of Pathology, GSVM Medical College, Kanpur.

5. Associate Professor, Department of Pathology, Rama Medical College Hospital \& Research Centre, Hapur. UP.

\section{NAME ADDRESS EMAIL ID OF THE}

\section{CORRESPONDING AUTHOR:}

Dr. Sonal Amit, 120/243, Lajpat Nagar,

Kanpur-208005.

E-mail: drsonalamit@gmail.com

Date of Submission: 16/03/2015.

Date of Peer Review: 17/03/2015.

Date of Acceptance: 27/03/2015.

Date of Publishing: 09/04/2015. 